\title{
APLIKASI INFORMASI RUMAH BEROBAT DI KOTA LAMONGAN BERBASIS ANDROID
}

\author{
Guntur P Kurniawan', Kemal Farouq Mauladi² \\ 1) Program Studi Teknik Informatika Universitas Islam Lamongan \\ ${ }^{2)}$ Dosen Fakultas Teknik Prodi Teknik Informatika Universitas Islam Lamongan \\ E-mail:Pryogaguntur@gmail.com ${ }^{1}$,Kemalfarouq_mauladi@yahoo.co.id ${ }^{2}$
}

\begin{abstract}
ABSTRAK
Smartphone menjadi salah satu alternatif yang dapat di aplikasikan dalam metode pembelajaran. multimedia interaktif juga bisa menjadi sarana penunjang kegiatan pembelajaran bagi masyarakat tak terkecuali media informasi. Oleh sebab itu, penulis memiliki inisiatif untuk membuat sebuah aplikasi yang berguna untuk pengenalan dan media informasi rumah berobat di Kota Lamongan menggunakan android, yang sekarang banyak digunakan oleh masyarakat. Aplikasi informasi rumah berobat berbasis android ini dibuat dengan menggunakan Eclipse sebagai pembangun mobile. Untuk perancangannya menggunakan metode terstruktur yang menggunakan Google Maps sebagai alat bantu untuk navigasi atau pemetaan tempat rumah sakit. Aplikasi informasi rumah berobat pada menu utama di kelompokkan berdasarkan list rumah sakit. Setelah itu baru akan muncul nama-nama rumah sakit di Kota Lamongan. Aplikasi ini diharapkan dapat menjadi media belajar dan informasi yang mengembalikan ketertarikan masyarakat dan dapat terus di-upgrade mengikuti perkembangan versi android selanjutnya dikarenakan hingga saat ini ada rumah berobat baru dan android masih terus mengalami perkembangan, hal ini diiringi dengan peningkatan kemampuan pada perangkat.
\end{abstract}

Kata Kunci : Aplikasi Rumah Sakit, Pengenalan, Android

\begin{abstract}
Smartphones become one of the alternatives that can be applied in teaching methods. interactive multimedia could also be a means of supporting learning activities for the public information media is no exception. Therefore, the writer had the initiative to create a useful application for the recognition and information media of health center in Lamongan town using android, which is used by people. Application information of health center android-based is built using Eclipse as mobile builder. For its design using a structured method that use Google Maps as a tool for navigation or mapping a hospital location. Application information of health center on the main menu are grouped based on the hospital list. After that will appear the names of the hospitals in Lamongan town. This application is expected to be a medium of learning and information restoring public interest and may continue to be upgraded following the development of the next version of Android because until now there is a new health center and android has continued to develop, it is accompanied by increased capabilities on the device.
\end{abstract}

Keywords : Hospital Application, Introduction, Android 


\section{PENDAHULUAN}

Perkembangan teknologi informasi saat ini sangat berguna bagi semua kalangan masyarakat. Sekarang ini teknologi informasi telah menjadi salah satu kebutuhan yang sangat penting dalam kehidupan sehari-hari. Teknologi informasi dapat mempermudah manusia dalam mengerjakan pekerjaannya. Sehingga, teknologi informasi dapat diimplementasikan dalam berbagai bidang, salah satunya dalam dunia media Android sebagai sarana informasi.

Rumah Sakit perlu adanya media informasi untuk memberikan Informasi mengenai keberadaan lokasi, pelayanan medis, maupun nomer telepon yang dapat di hubungi dalam keadaan darurat. Dari semua web rumah sakit yang dianalisis, belum semua web memuat fitur khusus pencarian lokasi dan hanya menampilkan informasi serta fasilitas yang tersedia. Namun, sejauh yang kita ketahui belum ditemukannya media pencarian lokasi dan informasi rumah sakit di Kota Lamongan berbasis Android.

Adapun tujuan dan manfaat dari penelitian ini adalah membuat sistem aplikasi yang dapat memberikan informasi rumah sakit di Kota Lamongan, manfaat yang dapat diperoleh dengan adanya aplikasi informasi ini adalah sebagai sarana informasi dan pengenalan rumah berobat yang ada di Kota Lamongan ini.

\section{PEMBAHASAN}

Kota Lamongan merupakan Kota kecil Ibukota Kabupaten Lamongan yang luas wilayah kurang lebih $1.812,80 \mathrm{Km}^{2}$ setara $181.280 \mathrm{Ha}$ atau $\pm 3.78 \%$ dari luas wilayah Propinsi Jawa Timur dengan panjang garis pantai sepanjang $47 \mathrm{Km}$. Batas wilayah administratif Kabupaten Lamongan adalah :

- Sebelah Utara : Berbatasan dengan Laut Jawa

- Sebelah Timur : Berbatasan dengan Kabupaten Gresik

- Sebelah Selatan : Berbatasan dengan Kab. Jombang dan Kab. Mojokerto

- Sebelah Barat : Berbatasan dengan Kab. Bojonegoro dan Kab. Tuban.
Kota Lamongan memiliki banyak instasi kesehatan yang dipelopori oleh Dinas Kesehatan sebagai pusat layanan kesehatan di seluruh Lamongan. Baik instasi kesehatan Rumah Sakit maupun layanan kesehatan yang masih berstatus Klinik kesehatan.

Sistem informasi layanan kesehatan di Kota Lamongan belum merata sehingga banyak rumah sakit ataupun Klinik dan tempat bersalin yang kurang dikenal oleh masyarakat di Kota Lamongan. Adapun masyarakat di Kota Lamongan hanya mencari rumah berobat di Instasi Kesehatan umum atau milik Pemerintah Kota Lamongan, sehingga Instasi Kesehatan swasta seperti Klinik atau rumah bersalin yang kurang dikenal oleh masyarakat Kota Lamongan.

\section{Perancangan Sistem}

Proses perancangan sistem ini adalah proses desain pengembangan perangkat lunak. Desain sistem perangkat lunak yang dibuat nantinya akan dijadikan sebagai acuan pengembang dalam penulisan kode. Desain sistem perangkat lunak ini harus sesuai karakteristik perangkat lunak yang akan dibuat serta mampu mempermudah dan memperjelas pengembang dalam proses pembuatan perangkat lunak. Penelitian ini menggunakan desain sistem model Unified Model Language $(U M L)$ dikarenakan model ini paling sesuai digunakan untuk mengembangkan sistem berorientasi objek

\section{Use Case Diagram}

Use case menggambarkan bagaimana seorang pengguna berinteraksi dengan sistem dengan cara menentukan langkah- langkah yang diperlukan untuk mencapai suatu tujuan tertentu. Variasi-variasi dalam urutan langkah yang terjadi antara aktor dan sistem merupakan sebuah skenario. Diagram use case memberikan suatu gambaran besar tentang fungsionalitas yang diharapkan dari sebuah sistem dilihat dari sudut pandang pengguna. Berikut ini merupakan gambaran dari desain aplikasi informasi rumah berobat berbasis android: 


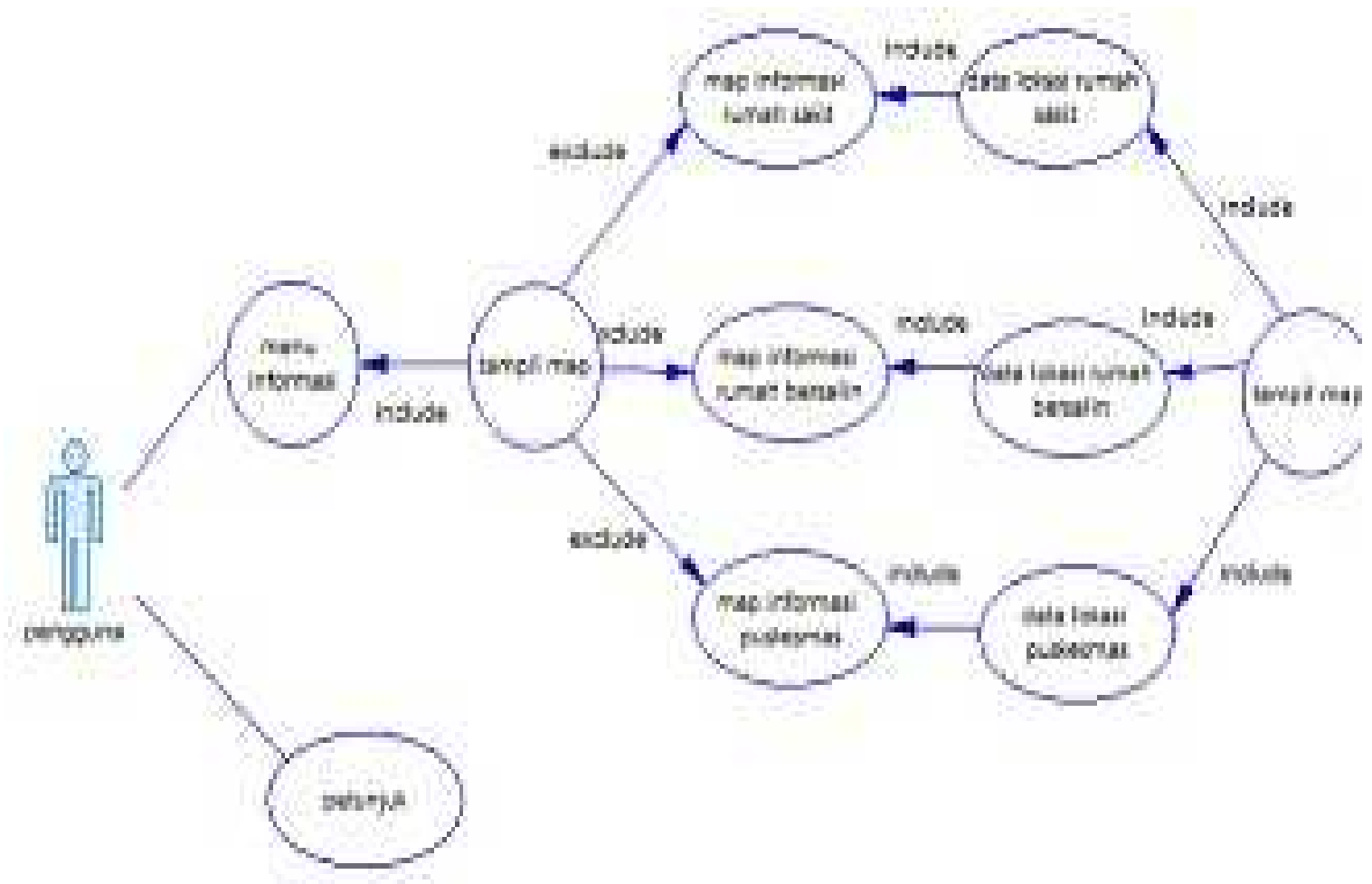

Gambar 1. Use Case Diagram

\section{Activity Diagram}

Activity diagram menggambarkan berbagai alir aktivitas dalam sistem yang sedang dirancang, bagaimana masing-masing alir berawal, decision yang mungkin terjadi, dan bagaimana mereka berakhir. Activity diagram juga menggambarkan berbagai alir aktivitas dalam sistem yang sedang dirancang, bagaimana masing-masing alir berawal, percabangan yang mungkin terjadi, dan bagaimana mereka berakhir. Activity diagram juga dapat menggambarkan proses paralel yang mungkin terjadi pada beberapa eksekusi.

Activity diagram juga dapat menggambarkan proses paralel yang mungkin terjadi pada beberapa eksekusi. Activity diagram merupakan state diagram khusus, di mana sebagian besar state adalah action dan sebagian besar transisi di-trigger oleh selesainya state sebelumnya (internal processing). Activity diagram menggambarkan berbagai alir aktivitas dalam sistem yang sedang dirancang, bagaimana masing-masing alir berawal, decision yang mungkin terjadi, dan bagaimana mereka berakhir. Activity diagram juga menggambarkan berbagai alir aktivitas dalam sistem yang sedang dirancang, bagaimana masing-masing alir berawal, percabangan yang mungkin terjadi, dan bagaimana mereka berakhir. Oleh karena itu activity diagram tidak menggambarkan behaviour internal sebuah sistem (dan interaksi antar subsistem) secara eksak, tetapi lebih menggambarkan proses-proses dan jalur-jalur aktivitas dari level atas secara umum. Menggambarkan proses bisnis dan urutan aktivitas dalam sebuah proses. Dipakai pada business modeling untuk memperlihatkan urutan aktivitas proses bisnis. Struktur diagram ini mirip flowchart atau Data Flow Diagram pada perancangan terstruktur. 


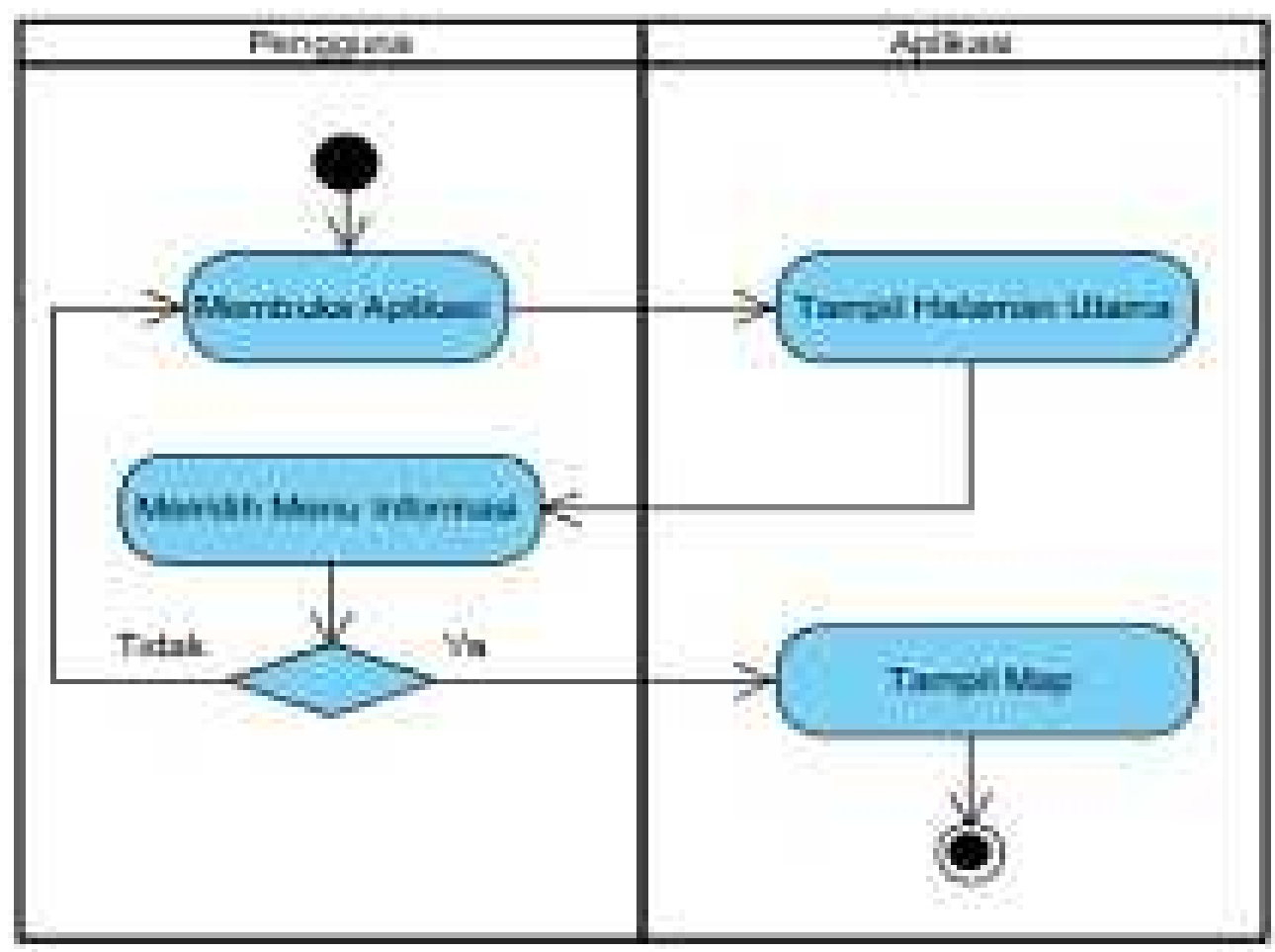

Gambar 2. Activyty Diagram

\section{Sequence Diagram}

Sequence diagram merupakan salah satu yang menjelaskan bagaimana suatu oprasi itu dilakukan, mesaage (pesan) apa yang dikirim dan kapan pelaksanaanya. Diagram ini diatur berdasarkan waktu. Obyek-obyek yang berkaitan dengan proses berjalanya oprasi diurutkan dari kiri ke kanan berdasarkan waktu terjadinya dalam pesan yang terurut.

Sequence diagram (diagram urutan) juga dapat diartikan sebagai suatu diagram yang memperlihatkan atau menampilkan interaksiinteraksi antar objek di dalam sistem yang disusun pada sebuah urutan atau rangkaian waktu. Interaksi antar objek tersebut termasuk pengguna, display, dan sebagainya berupa pesan/message. Sequence Diagram digunakan untuk menggambarkan skenario atau rangkaian langkah-langkah yang dilakukan sebagai sebuah respon dari suatu kejadian/event untuk menghasilkan output tertentu. Sequence Diagram diawali dari apa yang me-trigger aktivitas tersebut, proses dan perubahan apa saja yang terjadi secara internal dan output apa yang dihasilkan. Diagram ini secara khusus berasosiasi dengan use case diagram. Sequence diagram juga memperlihatkan tahap demi tahap apa yang seharusnya terjadi untuk menghasilkan sesuatu didalam use case.

Sequence diagram biasanya digunakan untuk tujuan analisa dan desain, memfokuskan pada identifikasi method didalam sebuah sistem. Adapun beberapa sequence diagram dari sistem ini adalah sebagai berikut: 


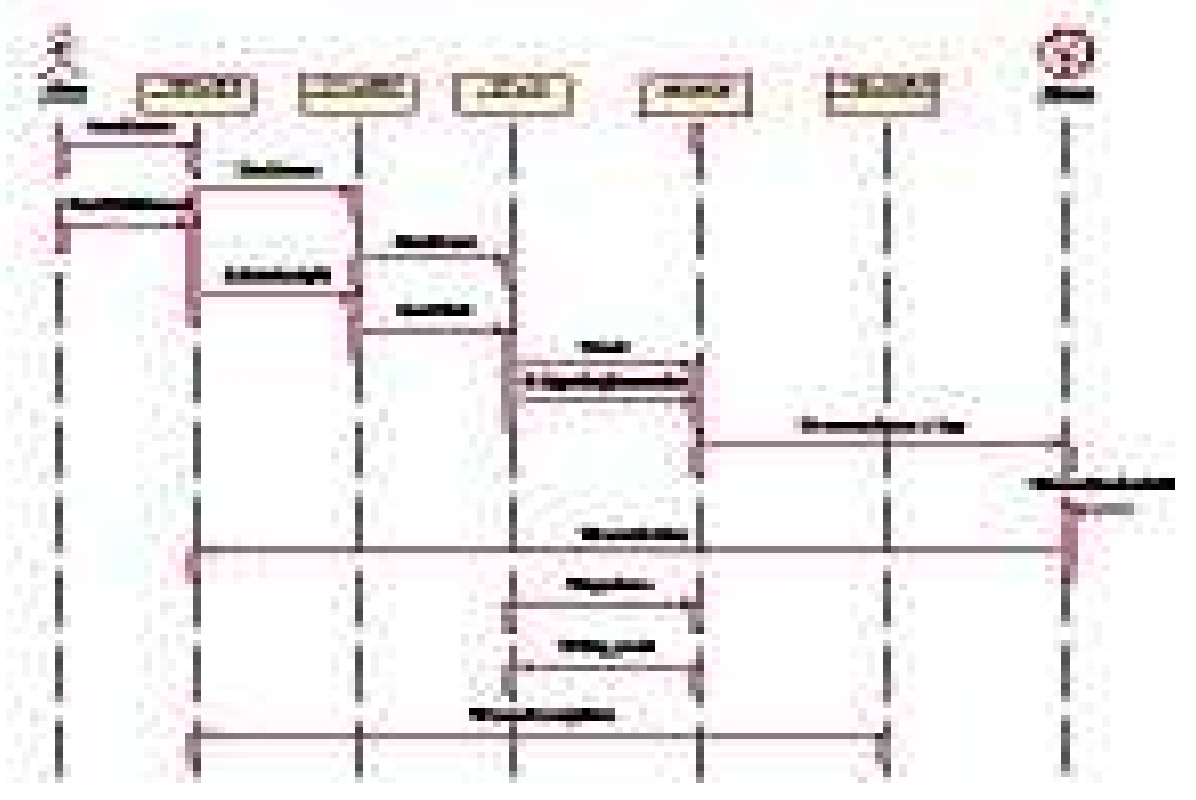

Gambar 3. Sequence Diagram

\section{Perancangan Antarmuka/Interface}

Rancangan masukan bertujuan untuk memenuhi kebutuhan pemakai dalam berinteraksi dengan sistem yang telah dibuat. Rancangan ini sangat penting dalam sistem pengolahan data, adapun input data yang dimasukkan ke dalam sistem harus dipersiapkan dengan baik agar output yang dihasilkan sesuai dengan yang diharapkan. Untuk memudahkan user dalam menggunakan sistem informasi geografis pemetaan lokasi rumah berobat di Kota Lamongan diperlukan adanya fasilitas penambahan data, menyimpan data dan manipulasi data lainnya yang di aplikasikan dalam bentuk form. Adapun rancangan masukan yang dibuat untuk sistem informasi geografis pemetaan lokasi rumah berobat di Kota Lamongan ini adalah sebagai berikut :

Tampilan Menu utama

Berikut adalah tampilah halaman utama aplikasi informasi rumah berobat di Kota Lamongan berbasis Android:

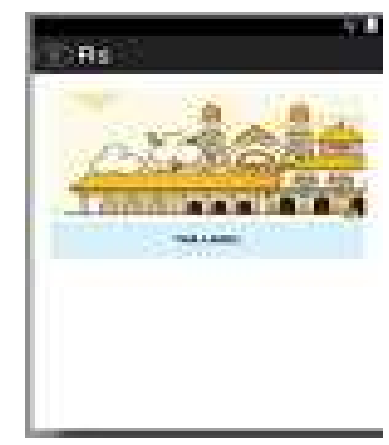

Gambar 4. Menu Utama
Pada Gambar 4 merupakan halaman yang digunakan untuk menampilkan menu-menu pada aplikasi informasi rumah berobat di Kota Lamongan ini.

\section{Tampilan Menu Explore Andrid}

Berikut adalah tampilah halaman Menu Explore Andrid:



Gambar 5. Menu Explore Android

Menu List Rs

Berikut adalah tampilah halaman List Rs berbasis android: 




Gambar 6. Menu List Rs

Pada Gambar 6 merupakan halaman yang digunakan untuk menampilkan kategori rumah sakit di Kota Lamongan.

Menu Help

Berikut adalah tampilah halaman Menu Help aplikasi informasi rumah berobat di Kota Lamongan berbasis android:

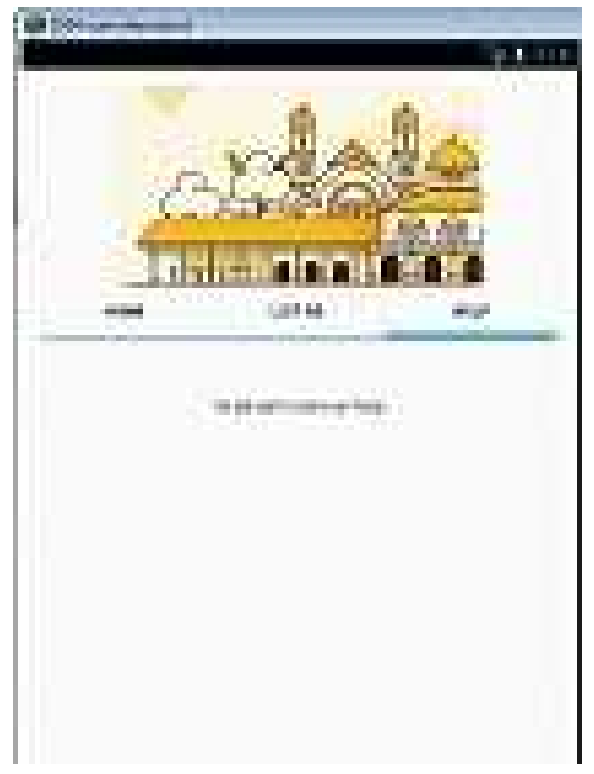

Gambar 7. Menu Help

Pada Gambar 7 merupakan halaman yang digunakan untuk menampilkan informasi mengenai aplikasi informasi rumah sakit di Kota Lamongan.

\section{Menu About Rumah Sakit}

Berikut adalah tampilah halaman menu about aplikasi informasi rumah berobat di Kota Lamongan berbasis android:

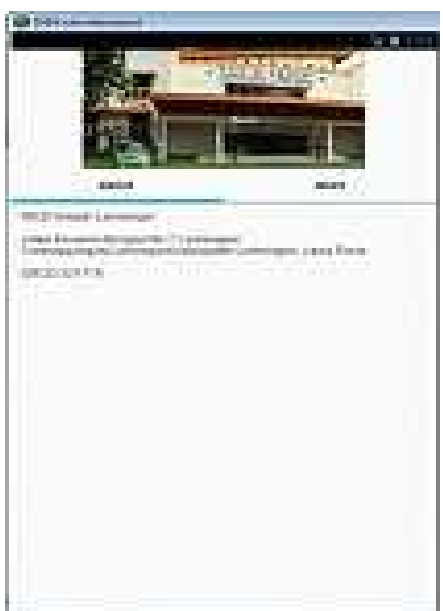

Gambar 8. Menu About

Pada Gambar 8 merupakan halaman yang digunakan untuk menampilkan informasi rumah sakit yang dipilih secara detail.

\section{Menu Maps Rumah Sakit}

Berikut adalah tampilah halaman Menu Maps rumah sakit Aplikasi informasi rumah berobat di Kota Lamongan berbasis android:

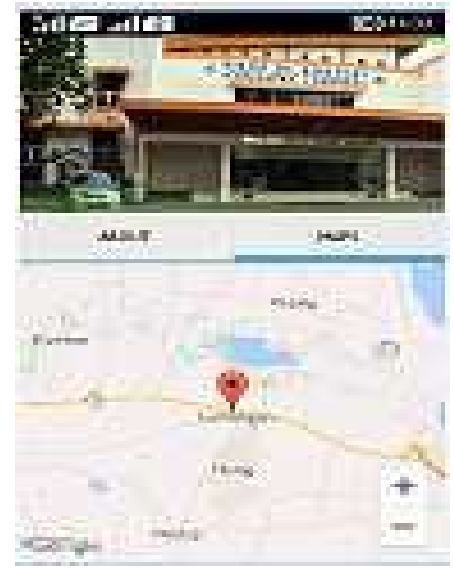

Gambar 9. Menu Maps Rumah Sakit

Pada Gambar 9 merupakan halaman peta dari google map yang digunakan untuk menampilkan peta berdasarkan data rumah sakit di Kota Lamongan yang dipilih.

\section{KESIMPULAN}

Berdasarkan tujuan, hasil, perancangan sistem, implementasi, dan uji coba dari Aplikasi Informasi rumah berobat di Kota Lamongan Berbasis Android yang telah dilakukan maka diperoleh kesimpulan sebagai berikut : Aplikasi pencarian lokasi rumah sakit merupakan aplikasi Sistem Informasi Geografis rumah berobat di Kota Lamongan Berbasis Android 
yang dapat berjalan dengan baik pada sistem operasi android minimal versi jellybean (4.2). Aplikasi ini dilengkapi fitur untuk menampilkan informasi objek berupa nama objek, alamat, dan rute dari lokasi user menuju lokasi objek.

Perancangan Aplikasi Informasi rumah berobat di Kota Lamongan Berbasis Android telah berhasil dibuat dengan menggunakan Eclipse dan Software Development Kit (SDK).

Aplikasi pencarian rumah sakit memberikan kemudahan bagi pengguna dalam mencari lokasi rumah berobat di Kota Lamongan sebab dari pengguna mengatakan aplikasi ini sangat membantu dalam mencari lokasi rumah berobat di Kota Lamongan.

\section{DAFTAR PUSTAKA}

Anonim, "Android Developers - Location | Android Developers", http://developer.android.com / reference / android / location / Location.html, 9 Maret 2016.

Mulyadi 2010, Membuat Aplikasi untuk Android, Multimedia Center, Yogyakarta.

Safaat, N., 2010, Membangun Aplikasi Mobile Berbasis Android, Informatika Bandung, Bandung.

https://id.wikipedia.org/wiki/rumah_sakit

https://library.binus.ac.id/eColls/eThesisdoc/B ab2/2012-1-00180-if\%20bab\%202.pdf

http://hanniyypurple.blogspot.co.id/2012/06/p engertian-geografi-menurut-para-ahli http://www.sarjanaku.com/2012/11/peng ertian-informasi-menurut-para-ahli.html https://id.wikipedia.org/wiki/Kabupaten_ Lamongan 
